\title{
İmplante Edilebilir Kardiyoverter Defibrilatörü Olan Hastalarda Ölüm Kaygısı ve Bakım
}

\author{
Mediha Sert, $\odot$ Zeynep Özer
}

Akdeniz Üniversitesi Hemşirelik Fakültesi, İç Hastalıkları Hemşireliği Anabilim Dalı, Antalya, Turkey

\begin{abstract}
Özet
Kardiyovasküler hastalıklar, oldukça yüksek insidans, mortalite ve morbidite oranlarına sahip, ölümle sonuçlanabilen önemli bir hastalık grubudur ve tüm dünyada en başta gelen ölüm nedenleri arasında yer alır. Dünya Sağlık Örgütü verilerine göre, 2016 yılında 17.6 milyon kişinin ölümü kardiyovasküler hastalıklar nedeniyle gerçekleşmiş olup, bu değerin on yılda artarak 23 milyona ulaşabileceği bildirilmiştir. Bu durum da kardiyovasküler hastalıkların önlenmesi, tedavisinin etkili ve devamlı sürdürülmesinin öneminin bir göstergesidir. Her hastalıkta olduğu gibi kardiyovasküler hastalıklarda da uygulanan tanı ve tedavi yöntemleri bireyleri psikososyal açıdan etkiler. Ölümcül aritmi ve ileri düzey kalp yetersizliklerinin tedavisinde sıklıkla kullanılan tedavi yöntemlerinden biri olan implante edilebilir kardiyoverter defibrilatörler, bireylerin yaşamlarını etkileyerek yaşam biçimi değişiklikleri gerektiren ve şoklama özelliği ile bireyleri ölümle karşı karşıya kalmaları halinde koruyabilen cihazlardır. Özellikle şoklama sonrasında gelişen ölüme ilişkin artan düşünceler, bireyleri psikososyal açıdan etkileyerek güvensizlik, çaresizlik, yaşama yönelik kontrolünü kaybetme, yakınlarına bağlı kalarak yük olma endişesi gibi kaygılara yol açabilir. Artan kaygı, bireylerin yaşam kalitesini azaltır, iş ve günlük yaşamlarını, tedavisini ve prognozunu olumsuz yönde etkiler. Bu nedenlerle sağlık çalışanlarının, kalp hastalığı olan bireylerin yaşama ilişkin kalbe yükledikleri anlamın bilincinde olması, bireylerin ölüme yönelik kaygı düzeylerini değerlendirerek kaygı ile baş etme yöntemleri doğrultusunda girişimler planlaması gereklidir. Böylece bireylerin kaygı düzeyleri kontrol edilerek, karşılaşılabilecek problemlerin önüne geçileceği, tedavinin daha etkili sürdürülerek bireylerin yaşamlarının ve sunulan hizmetin kalitesinin de bu doğrultuda artırılacağı ön görülmektedir.
\end{abstract}

Anahtar sözcükler: Hemşirelik; hemşirelik bakımı; implante edilebilir kardiyoverter defibrilatör; ölüm kaygısı.

\section{Death Anxiety and Care in Patients With Implantable Cardioverter Defibrillator}

\begin{abstract}
Cardiovascular diseases are an important group of diseases that have a high incidence, mortality and morbidity, which can result in death and are among the leading causes of death worldwide. According to World Health Organization data, 17.6 million people died in 2016 due to cardiovascular diseases and it was reported that this value could reach 23 million in a decade. This is an indication of the importance of prevention of cardiovascular diseases and the continuation of effective and continuous treatment. As in every disease, the diagnosis and treatment methods applied in cardiovascular diseases affect individuals psychosocially. Implantable cardioverter defibrillators, which are frequently used in the treatment of fatal arrhythmias and advanced heart failure, are devices that require life style changes by affecting the lives of individuals and can protect individuals if they are faced with death by shocking feature. Increasing thoughts about death, especially after shock, can affect individuals psychosocially and cause concerns such as distrust, helplessness, loss of control over life, and
\end{abstract}


fear of being burden to their relatives. Increased anxiety decreases the quality of life of individuals and affects their daily lives, treatment and prognosis in a negative way. For these reasons, health care professionals, should be aware of the meaning of the heart about of life for heart disease individuals, individuals should plan initiatives to deal with anxiety by evaluating their anxiety levels. Thus, by controlling the anxiety levels of individuals, problems that may be encountered will be prevented, It is foreseen that, the treatment will be sustaining more effective for individuals and the quality of life and the service will be increased accordingly.

Keywords: Death anxiety; implantable cardioverter defibrillator; nursing; nursing care.

Cite this article as: Sert M, Özer Z. Death Anxiety and Care in Patients With Implantable Cardioverter Defibrillator. Turk J Cardiovasc Nurs 2019;10(22):78-86.

$\mathrm{K}^{\mathrm{s}}$ ardiyovasküler hastalıklar (KVH) hemen her toplumda sıklıkla görülen, mortalite ve morbidite oranları oldukça yüksek olan ve ölüm nedenleri arasında en başta gelen bir hastalık grubudur. ${ }^{[1,2]}$ Dünyada 2015 yılında gerçekleşen ölümlerin \%31'i, Türkiye'de ise \%47.73'ü KVH nedeniyle gerçekleşmiş olup, yaklaşık on yıl sonra bu değerlerin daha da artacağı ön görülmektedir. ${ }^{[2-4]}$ Bu nedenle, KVH'nin önlenmesi, insidansının, mortalite ve morbidite oranlarının azaltılması ve buna ilişkin kullanılan tedavi stratejilerinin geliştirilmesi oldukça önem taşımaktadır.

Ventriküler aritmi ve ileri düzey kalp yetersizlikleri gibi hastalıklara bağlı gelişebilecek ani ölümlerin engellenmesi ve mortalite oranlarının düşürülmesi amacıyla kullanılan tedavi stratejileri arasında, implante edilebilir kardiyoverter defibrilatörler (ICD) yer almaktadır. ${ }^{[5,6]}$ ICD kullanımının yüksek riskli hastalarda \%30-54 oranında ani kardiyak ölüme ilişkin mortaliteyi azalttığı belirlenmiştir. ${ }^{[5]}$ Oldukça etkin bir tedavi yöntemi olmasına rağmen ICD, her hastalıkta ve tedavide olduğu gibi bireylerin yaşamını etkileyerek depresyon, korku, anksiyete ve kaygı gibi psikososyal problemlere de yol açabilmektedir. ${ }^{[7,8]}$

İmplante edilebilir kardiyoverter defibrilatörler vücuda kalıcı olarak yerleştirilen cihazlardır. Bu nedenle cihaza uyum beraberinde yaşam şekli değişikliklerini gerektirmekte, bu durum da bireylerin çeşitli zorluklar ile karşı karşıya kalmasına neden olabilmektedir. ${ }^{[9]}$ Tüm bu zorluklar, hastaları psikososyal açıdan etkileyerek yaşam kalitelerini olumsuz yönde etkileyebilmektedir. İmplantasyon sonrasında yaşanılan değişiklikler, bireylerde anksiyete ve kaygıya neden olduğu ve tekrarlayan şoklarla ilişkilendirildiğ ${ }^{[10]}$ gibi, tekrarlı şoklar da psikososyal sorunlara neden olabilmektedir. ${ }^{[11,12]}$

Carroll, Hamilton (2008) ve Schron ve ark. (2002) tarafından yapılan çalışmalarda, şoklama sonrasında veya şoklama sayısının artması durumunda bireylerin olumsuz etkilendiği ve yaşam kalitelerinin de bu doğrultuda azaldığı bildirilmiştir. ${ }^{[13,14]}$ Ayrıca, implantasyon sonrası gelişen herhangi bir şoklamanın kardiyak ölüm riskini iki kat arttırdığı, fiziksel ve zihinsel işlevlerde önemli düzeyde düşüşe neden olduğu ve geleceğe ilişkin belirsizlik duygularında da artışa yol aç- tığı belirlenmiştir. ${ }^{[14,15]}$

İmplante edilebilir kardiyoverter defibrilatöre bağımlı hastalarda daha sık olmakla birlikte, yaşamlarının cihaza bağlı olması, cihazın tükenebilir bir pil ile çalışması, şoklama sonucu pilin tükenebileceği düşüncesi; ${ }^{[16]}$ şoklamaya ilişkin ise ağı hissetme, zamanının belirsizliğine yönelik endişe duyma, şokun ev dışında gerçekleşmesi ve şoklama sırasında bilinç kaybına ilişkin güvensizlik hissi gibi düşünceler bireyleri olumsuz etkileyerek anksiyete ve kaygıya neden olabilmektedir. ${ }^{[7,10]}$ Bireylerin artan anksiyete ve kaygı düzeylerinin de implantasyon sonrası bir yıl içindeki mortalite oranlarını arttırdığı bildirilmektedir. ${ }^{[5,17]}$

Hastaların ölümle sonuçlanabilecek ciddi aritmiler ile karşı karşıya kalması durumunda devreye girerek çalışan ICD'ye ilişkin bireylerin, cihaza uyumlarının sağlanması ilk başta uygulanacak girişimler arasında yer almalıdır. ${ }^{[9,18]}$ Buna yönelik hemşireler, bireylerin cihaz ile ilişkili eğitimlerini sağlamalı, doktora başvurulması gereken durumları ve dikkat edilmesi gereken hususlar hakkında bireyleri bilgilendirmelidir. Ayrıca cihaz implantasyonu sonrası kaygı, korku ve anksiyete düzeylerinin artması ile gelişen psikososyal problemlere ilişkin bireylerin kaygı düzeylerini belirlemeli, kaygıya neden olan ve artıran faktörleri uzaklaştırmalı ve baş etme biçimlerini de geliştirmeye yönelik girişimlerde bulunmalıdır. ${ }^{[9,18-20]}$ Ancak bu sayede hastalara bütüncül yaklaşım sağlanabilir, bireylerin kaygı düzeyleri azaltılarak yaşam kaliteleri artırılabilir, tedavinin etkili ve devamlı sürdürülmesi sağlanabilir.

\section{İmplante Edilebilir Kardiyoverter Defibrilatörler}

İmplante edilebilir kardiyoverter defibrilatörler, 1980 yıllarının sonunda kullanılmaya başlanan ve günümüzde kardiyak resenkronizasyon tedavisinde kullanımı süren bir invaziv tedavi yöntemidir. ${ }^{[21,22]}$ Kalbin çalışmasını ve elektriksel uyarımı devamlı olarak izler, ritim bozukluğunu algılayarak, bradikardi/taşikardi sonlandırıcı uyarı, kardiyoversiyon ve ya defibrilasyon (şoklama) uyarısı gibi özelliklerinden en uygun olanını tedavide uygulayarak sinüs ritmini sürdürür. [23] Özellikle ani kardiyak ölüme sebep olabilecek ventriküler taşikardi ve ventriküler aritmi ataklarının algılanarak 
önlenmesi için geliştirilmiş birincil tedavi seçenekleri arasında olup, bu durumlarda başarı etkinliği \%97-98 olarak belirlenmiştir. ${ }^{[15,24]}$

\section{İmplante Edilebilir Kardiyoverter Defibrilatör Kullanım Önerileri}

İmplante edilebilir kardiyoverter defibrilatörler, daha önce kardiyak arrest öyküsü olmayan, ani kardiyak ölüm riski yüksek hastalarda birincil koruma amaçlı ve arrest öyküsü olan hastalarda ikincil korunma amaçlı kullanılmaktadır. Amerikan Kalp Derneği kılavuzunda ICD kullanım endikasyonlarına ilişkin öneriler yer almaktadır. ${ }^{[6]}$

İmplante edilebilir kardiyoverter defibrilatöre ilişkin Sınıf I, Sınıf II ve Sınıf III olmak üzere endikasyon önerileri mevcuttur. ICD endikasyonları arasında önemli bir yeri olan Sınıf I endikasyon önerileri aşağıda yer almaktadır. Önerilerin bir çoğu, hastalarda bir yıldan daha uzun süreli sağ kalım bekleniyor olması halinde implantasyonunun endike olduğunu bildirmektedir. ${ }^{[6,25,26]}$

- Ventriküler fibrilasyon ya da hemodinamiyi bozan unstabil ve sürekli ventriküler taşikardi nedeniyle gelişen kardiyak arrest

- Yapısal kalp hastalığı olan bireylerde hemodinamiyi bozan veya bozmayan sürekli ventriküler taşikardi atakları

- Hemodinamiyi bozan ventriküler taşikardi veya ventriküler fibrilasyon nedeniyle gelişen senkop

- Miyokard enfarktüsü üzerinden en az 40 gün, revaskülarizasyon üzerinden en az 90 gün geçmiş, sol kalp Ejeksiyon Fraksiyonu (EF) değeri \%35 veya daha az ve optimal medikal tedaviye rağmen New York Kalp Birliği Sınıflamasına göre fonksiyonel kapasitesi Sınıf II ve III kalp yetersizliği semptomları olan hastalar

- Miyokard enfarktüsü üzerinden en az 40 gün, revaskülarizasyon üzerinden en az 90 gün geçmiş, sol kalp EF değeri \%30 veya daha az ve optimal medikal tedaviye rağmen fonksiyonel kapasitesi Sınıf I kalp yetersizliği semptomları olan hastalar

- Miyokard enfarktüsü nedeniyle non stabil ventriküler taşikardi öyküsü olan, sol kalp EF'si \%40 veya daha az ve elektro fizyolojik çalışmalar ile indüklenebilen ventriküler taşikardi veya ventriküler fibrilasyonu olan hastalar

- Ventriküler taşikardi veya ventriküler fibrilasyon nedeniyle kardiyak arrest öyküsü olan ya da hemodinamik olarak kararsız ventriküler taşikardisi olan non-iskemik kardiyomiyopatili hastalar

- Elektrokardiyografide erken re-polarizasyon paterni olan ve arrest öyküsü veya devam eden ventriküler aritmisi olan hastalarda endikedir.

\section{ICD İmplantasyonu Sonrası Dikkat Edilmesi Gereken Hususlar}

Kardiyoverter defibrilatör implantasyonu sonrası, hastaların cihaza ilişkin uyumları oldukça önemlidir ve bunun için yaşam şekli değişiklikleri gerekmektedir. Bu süreçte hastaların eğitimi olası komplikasyonların önlenmesi açısından gereklidir. Hastalar, hemşireler tarafından ICD'nin kullanım amacı, nasıl bir cihaz olduğu ve çalışma şekli, şoklamanın nasıl bir his olduğu ve bu durumda ne yapması gerektiği, erken dönemde ve geç dönemde dikkat edilecek hususlar ve günlük yaşamda gerekli değişikliklerin yapılması konularında bilgilendirilmelidir. $\left.{ }^{[9,} 27,28\right]$

İmplantasyon sonrası en az 3-4 gün bölge kuru tutulmalı, kıyafetler düzenli olarak değiştirilmeli, vücudu sıkmayan, hava alan kıyafetler tercih edilmeli, günlük olarak pansuman değiştirilmeli, insizyon bölgesi kızarıklık, akıntı, şişlik ve enfeksiyon açısından kontrol edilmeli, implantasyon yapılan taraftaki kol 90 dereceden daha fazla yukarıya kaldırılmamalı, aşırı itme, çekme veya bükme hareketinden kaçınılmalı, genellikle on gün sonra banyo uygun görülüyor olsa da hekimin bu konudaki önerisi dikkate alınmalı, implantasyon olan kol ile ağırlık taşınmamalı, ilk altı ay araba kullanılmamalı gerekli ise hekime danışılmalı, şoklama halinde bilinç kaybı ya da kendini iyi hissetmeme durumu mevcutsa hekime haber verilmeli ve stabil değilse acil yardıma başvurulmalıdır. $\left.{ }^{[9,} 18,27,28\right]$

Hastalara implantasyon sonrası pili olduğuna dair bir kart verilmekte, bu kartı yanında taşıması ve gerekli durumlarda pili olduğunu ifade etmesi önerilmektedir. El detektörleri ya da X-Ray cihazlarından geçilmemesi, elle aramanın talep edilmesi, matkap gibi güçlü aletlerin bölgeden uzak tutulması, elektrikli ya da gazlı cihaz bakımının/tamirinin yapılmaması, elektromanyetik alanlarda bulunulmaması, manyetik rezonans görüntülemenin yapılmaması, cep telefonunun bölgeye en az $15 \mathrm{~cm}$ uzaklıkta tutulması da dikkat edilmesi gereken diğer hususlar arasında yer almaktadır. Hasta ve hasta yakınlarının bu süreçte eğitimi mevcut cihaza uyumun ve yaşam kalitesinin sağlanmasında büyük önem taşımaktadır. ${ }^{[9,27-29]}$

\section{ICD Şoklaması Yaşayan Hastaya Yaklaşım}

Hastanın implantasyon sonrası 24 saat içinde uygun ya da uygun olmayan üç veya daha fazla şok alması durumunda hastaneye yatışı gerekebilir. Şoklama sırasında bilincini kaybetmeyen hastalar şoklamayı ani elektrik çarpması, göğüse yumruk ya da tekme atılması veya şimşek çakması şeklinde tariflemekte ve bu durum kaygılara yol açarak hastaları psikososyal açıdan etkilemektedir. ${ }^{[30,31]}$ 
İki veya daha çok şoklama alan hastanın kendini iyi hissetmesi halinde baş ağrısı ve baş dönmesi de yoksa doktorunu arayarak şoklama yaşadığını bildirmesi, takip eden hafta ya da gün içinde kontrole gitmesi; şoklama sonrası kendini kötü hissediyor ve baş dönmesi ile ağrı semptomlara eşlik ediyor ise acil yardım talep edilmesi, bilincini yitirmesi halinde kalp masajı yapılması uygulanacak girişimler arasında yer almaktadır. ${ }^{[32]}$

\section{ICD İmplantasyonu Sonrası Psikososyal Etkiler}

Kalp yaşamı doğrudan etkileyen, yaşama yönelik diğer organlara göre daha fazla anlam yüklenen olan bir organdır. Bu nedenle bireylerin kalp hastalıklarına ilişkin hayata yönelik kaygıları diğer hastalıklara oranla daha fazladır. Ayrıca kalp hastalıklarının ölüm nedenleri arasında ilk sırada yer alması bireylerin ölüme ilişkin kaygı düzeylerini daha da artırmaktadır. ${ }^{[33-36]}$

Her tedavide olduğu gibi ICD implantasyonunun, yaşamı etkileyen bir stres kaynağı olması, yaşam boyu yapay bir cihazın vücutta taşınacak olması ve devamlı takip gerekliliği gibi nedenlerle hastaların ölüm kaygısı, anksiyete, uyku problemleri gibi birçok psikososyal problemler yaşadığı ve kaygı insidanslarının diğer hasta gruplarına oranla daha fazla olduğu bildirilmiştir. ${ }^{[7-9]}$

Hastaların ICD ile ilişkili yaşadığı psikososyal problemlere yönelik başlıca risk faktörleri, 65 yaş altında olma, ICD'nin birincil koruma endikasyonu ile takılmış olması, sınırlı sosyal destek, düşük eğitim seviyesi, psikiyatrik hastalık öyküsü, düşük kardiyak fonksiyon ve sıklıkla ICD deşarjı yaşama şeklinde sıralanabilmektedir. ${ }^{[37,38]}$

Özellikle genç hastalarda daha sık olmak ile birlikte, cihazın belirli süreçlerde cerrahi girişimler ile değiştirilmesi gerekliliği, cihazın vücut üzerinde görünmesine bağlı beden algısında değişiklik olması, gebeliğe ilişkin riskler gibi durumlar da bireyleri kaygıya sürükleyen diğer etmenler arasında yer almaktadır. ${ }^{[19,29]}$ Abmad ve arkadaşları tarafından yapılan çalışmada ICD'ye uyumun yaşa bağlı olarak değişiklik gösterdiği bildirilmiş, ICD cihazının, yaşlı hastalar tarafından, yaşam süresini uzatarak olumlu katkı sağladığı, genç hastalar tarafından ise, dramatik yaşam değişikliklerine, bağımsızlığın azalmasına ve vücut imajı ile ilgili endişelere neden olarak olumsuz etkilediği bildirilmiştir. [39]

Cihazın şoklama özelliğinin olması, şoklamaya yönelik kaygıyı arttırmakta ve bireylerin, fiziksel, cinsel aktivitelerde kısıtlama geliştiği, günlük yaşam ve iş performanslarının ve yaşam kalitesinin olumsuz yönde etkilendiği, depresyon, zihinsel işlevlerde ve yaşam şekillerinde değişiklikler geliştiği, kontrol kaybı ve eşlerin aşırı koruması gibi durumlar ile de karşı karşıya kaldıkları bildirilmektedir. ${ }^{[7,40,41]}$

Duru ve ark. (2001) tarafından yapılan bir çalışmada Pacemaker (PM) ve ICD'li hastaların cihaza ilişkin yaşadığı psikososyal problemler, adaptasyon ve yaşam kaliteleri arasındaki farklar incelenmiştir. Bu çalışma sonucunda, depresyon düzeyi şoklama deneyimleyen ICD hastalarında $\% 6.6$, deneyimlemeyen ICD hastalarında \%6.5 ve PM hastalarında ise \%5.2; sosyal destek intiyacı şoklama deneyimleyen ICD hastalarında \%42.2, deneyimlemeyenlerde $\% 20$ ve PM hastalarında \%19.7; anksiyete bozukluğu ise şoklama deneyimleyen ICD hastalarında \%13.3 deneyimlemeyenlerde \%9.7 ve PM hastalarında \%13.1 olarak belirlenmiştir. Bunlara ek olarak ICD hastalarının, PM hastalarına oranla günlük aktivitelerden kaçınmanın ve pilin tükenmesi ya da arızalanmasına ilişkin endişelerin daha yüksek olduğu da gösterilmiştir. Ayrıca PM ve ICD hastalarının yaşam kaliteleri arasında anlamlı bir fark bulunmayıp bu durum, ICD'li hastaların cihazın ölüme yönelik koruma sağladığı düşünceleri ile ilişkilendirilmiştir. ${ }^{[42]}$

Hastaların ICD'ye ilişkin sıklıkla yaşadıkları psikososyal problemler ve bunlara ilişkin tutumları aşağıda verilmiştir: $[37,38]$

- Egzersiz yapmanın kalp atımını hızlandırarak şoklamaya neden olacağı düşüncesi ile fiziksel aktivitelerden kaçınma

- Şoklama anında yardıma ihtiyacının olacağı düşüncesi ile yalnız kalmaktan kaçınma

- Üzülme ve sinirlenmenin şoklamaya neden olacağı düşüncesine ilişkin kaygı yaşama

- Şoklama zamanının belirsizliğine ilişkin kaygı yaşama

- Cihazın gerektiğinde şoklama yapmayacağı düşüncesine ilişkin kaygı yaşama

- Şoklama sırasında yakındaki bireylere de etki edebileceği düşüncesiyle dokunmaktan kaçınma

- Şoklama ve şoklamaya bağlı mahcubiyet yaşama düşüncesine ilişkin kaygı yaşama

- Şoklamaya ilişkin istenilmeyen düşüncelerden kaçınma

- Cinsel aktivitenin şoklamaya neden olabileceği düşüncesi ile kaçınma

Schuster ve ark. yapmış olduğu çalışmada ICD hastalarının \%64'ünün hafıza sorunları, \%56'sının uyku problemi, $\% 57$ 'sinin depresyon yaşadığı ve aşırı korumacı ailesi olduğu, \%38'inin ölüm ve ölümle ilişkili endişe, \%46'sının şok korkusu, \%41'inin cihazın arızalanmasına ilişkin korku ve \%33'ünün de cinsel problemler yaşadığı bildirilmiştir. ${ }^{[43,44]}$ Yapılan çalışmalarda, ICD implantasyonu sonrası hastaların en sık öfke, korku ve kaygı yaşadıkları, ayrıca ICD şokunu yaşayan bireylerde, şoku yaşamayan bireylere oranla, şok sık- 
lığı ile doğru orantılı olarak kaygı ve korku gibi psikososyal problemlerin daha fazla olduğu ve bu durumun hastalarda ölüm kaygısına yol açtığı belirlenmiştir. ${ }^{[40,45,46]}$

\section{Ölüm ve Ölüm Kaygısı Kavramı}

Kaygı, "genellikle kötü bir şey olacakmış düşüncesiyle ortaya çıkan ve sebebi bilinmeyen gerginlik duygusu" olarak tanımlanmaktadır. ${ }^{[4]}$ Kişileri gergin bir duygu durumuna sürüklemekte, gerilim, titreme, taşikardi, stres ve çarpıntı hissi gibi belirtiler ile gelişebilmektedir. ${ }^{[48]}$ Kaygı, mevcut durumun değerlendirilmesi ile ortaya çıkan bir tepkidir. Ölen birisi ile karşılaşmak, bir yakınının kaybı gibi durumlar bireylerde ölüme ilişkin düşünceleri artırarak kaygı duygusunu tetiklemektedir. Bunlarla birlikte ölümün bilinmeyen bir olgu olması ve zamanının belirsiz olması bireylerin kaygı düzeylerini daha da artıran etmenler arasında yer almaktadır. Bireyler için ölüm korkutucudur, suçluluk, öfke, empati, üzülme gibi birçok duyguyu içinde barındırmaktadır. ${ }^{[48,49]}$

Ölüm kavramı ise, "yeniden canlandırma olasılığının olmadığı ve tüm yaşam fonksiyonlarının durduğu durum" olarak tanımlanmaktadır. ${ }^{[0]}$ Ölüm kaygısı bireylerde ölümün yaklaşmasına ilişkin düşünceler ya da ölüm ile karşı karşıya kalma gibi durumlarda gelişen bir duygudur ve bu duygu bireyleri olumsuz yönde etkilemektedir. Özellikle yaşamı tehdit eden hastalığı olan bireylerde, yaşama ilişkin kontrolü kaybetme, hareket kabiliyetini ve bağımsızlığı yitirme gibi fiziksel fonksiyonların kaybı da çaresizlik ve kaygı duygusunu tetiklemektedir. ${ }^{[49,51,52]}$

Ölüm kaygısı ölümün hoş olmayan bir durum olduğu ve acı verdiği düşünceleri ile gelişen, yaşamın sonu ve sevdiklerinden ayrılma düşüncelerinden de doğabilen bir durumdur. Bireylerde ölümü hatırlatarak kaygıya neden olan birçok olgu söz konusudur. Bu olguların en başında ölüme neden olabilecek hastalıklar gelmektedir. Ölüm kaygısı düzeyleri özellikle kronik hastalıkları olan bireylerde tanı ve prognozun belirsizliği, yaşamı tehdit eden bir hastalık olması, semptomlarda etkin tedaviye rağmen düzelme olmaması, ölüme ilişkin bireysel ve toplumsal düşünceler, yakın dönemde bir yakınının kaybı, ölüme ilişkin çaresizlik hissi ve

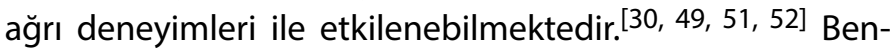
zer şekilde yaş, psikolojik olgun olma durumu, ölümcül bir hastalıkla karşı karşıya kalma ya da ani gelişen bir kayıp da ölüm kaygısını tetikleyebilmektedir. ${ }^{[53]}$ Ölüme ilişkin Arpacı ve ark. (2011) tarafından yapılan çalışmada, ölüm kaygısının çok boyutlu bir kaygı olduğu, bu boyutların ölümün bilinmezliği, ölüm anında acı çekme, yalnız kalma ve ölüm sonrası yok olma gibi alt boyutlarının olduğu bildirilmiştir. ${ }^{[48]}$ İmplante edilebilir kardiyoverter defibrilatör pil ile çalışan, gereken durumlarda titreşim ya da sesli uyarı ile bireyleri uyaran ve şoklama yapan bir cihazdır. Ani gelişen ve ölüme sebep olabilecek, bireyleri ölüm ile karşı karşıya getiren ritim bozukluklarında kullanılan bir cihaz olması da hastalarda ölüm olgusunu hatırlatarak ölüm kaygısını tetiklemektedir. Özellikle pile bağımlı bireylerde, pil olmadan yaşayamayacağı düşünceleri pile ilişkin tükenme, gerektiğinde devreye girmeme cihazın ses ya da titreşim ile verdiği uyarıların sıklığının artması ile doğru orantılı olarak ölümle karşılaşma düşünceleri ölüme ilişkin mevcut kaygı düzeylerini artırmaktadır. ${ }^{[9,19,54]}$

Cihazın şoklama özelliğinin olması ve bu özelliğinin ölümle karşılaşma anında devreye girmesi daha önce şok yaşamayan bireylerde şoklama hissinin nasıl olduğunun ve ne zaman karşılaşılacağının bilinmiyor olması, şoklamayı ev dışında yaşama, araba kullanırken şoklama yaşama kaygısı ve olası sonuçlarının düşünülmesi, şoklama sırasında yalnız olma kimseye haber verememe ve gereken zamanda şoklama olmamasına ilişkin kaygılar nedeniyle güvensiz hissetme gibi durumlar bireylerde ölüm kaygısı düzeylerini tetikleyen diğer etmenler arasında yer almaktadır. $[9,19,30,54]$

Kaygı düzeyinin artışı, bireylerin yaşamını oldukça olumsuz yönde etkileyerek iş performansında düşme, kişisel, sosyal ve maddi kayıplar, aktivitelerini yerine getirmede kısıtlama, depresyon, uyku problemleri gibi günlük yaşamlarında birçok problemler ile karşı karşıya kalmalarına neden olabilmektedir. ${ }^{[33,36,37]}$ Günümüzde ICD hastalarına yönelik çalışmalar oldukça sınırlı sayıda olmakla birlikte, yapılan çalışmalarda hastaların ölüm kaygısı ve çaresizlik gibi psikososyal problemler ile sıklıkla karşılaştıkları gösterilmiştir. [13, 40, 46, 55] Ayrıca, Kuhl, Dixit ve Walker (2006) tarafından yapılan çalışmada, kardiyak fonksiyonu düşük olan bireylerde kaygı ve depresyon düzeyinin daha yüksek olduğu da bildirilmektedir. ${ }^{[38]}$

\section{Ölüm Kaygısında Hemşirelik Girişimleri}

Ölüm kaygısı bireylerin ölüme karşı kontrolünün olmaması nedeniyle gelişen güçsüzlük, çaresizlik duyguları, fiziksel ya da mental yeterliliğin kaybı, kronik hatta ölümcül bir hastalığın varlığı ve buna yönelik yakınlarının bakımına bağlı kalma ve onlara yük olma kaygısı, ölümün zamansız, erken ya da geç geleceği düşünceleri, hayattaki amaç ve hedeflere ulaşamama korkuları, ölümün olumsuz bir deneyim olduğunun düşüncesi, ölüm sonrası hayata ilişkin korkular, yaratıcı ile karşılaşma düşünceleri gibi birçok etmen ile tetiklenen, bireylerin kendi ölümü ya da bir yakının ölümüne yönelik gelişen bir duygudur. ${ }^{[48,51]}$ 
Sürekli ya da aşırı duyulan kaygı, bireylerin psikolojisini olumsuz yönde etkileyebilmektedir. Bu nedenle bireylerin kaygıya ilişkin başlıca risk faktörlerinin farkında olunması, kaygı düzeylerinin düzenli olarak değerlendirilmesi ve gerekli müdahalelerin sürdürülmesi oldukça önem taşımaktadır. ${ }^{[48,56]}$ Bu aşamada kapsamlı bir kardiyovasküler rehabilitasyon programı önerilmekte, gevşeme ve stres yönetimi, cihaza ilişkin eğitim, bilişsel davranış̧̧ı terapi, sosyal desteğin güçlendirilmesi, ve egzersiz programlarının planlanması gibi yaklaşımların rehabilitasyon hedefleri arasında yer alması gerekmektedir. ${ }^{[44]}$

Fitchet ve ark. tarafından yapılan çalışmada, kardiyovasküler rehabilitasyon programlarına katılımın, ICD hastalarında egzersiz kapasitelerini arttırdığı, egzersize bağlı olan veya olmayan şoklama oranlarını, ani kalp durması riskini ve psikolojik problemleri azalttığı gösterilmiştir. ${ }^{[57]}$ Kardiyovasküler rehabilitasyon uygulamaları ile, aritmilerin neden olduğu iskemik atakların sıklığının da azaltıla bilineceği bildirilmektedir. ${ }^{[44,57]}$

Kardiyovasküler rehabilitasyon programlarının uygulanmasında, bireylerin hastalıklara ve tedavilere ilişkin yaşadığı kaygı ve korkuların değerlendirilmesi ve önlenmesinde hemşirelere büyük rol ve sorumluluklar düşmektedir. Bireyleri fiziksel ve psikolojik açıdan olumsuz yönde etkileyen ölüm kaygısında uygulanacak hemşirelik girişimlerinde amaç, bireylerin ölüm kaygı düzeyleri ve etkileyen faktörlerin belirlenerek, hastaların güçlendirilmesi ve kaygı ile baş etme tutumlarının geliştirilerek kaygı düzeylerinin azaltılmasıdır. ${ }^{[30,31,48,51]}$

Ölüme ilişkin kaygı yaşayan bireylerde ilk olarak uygulanacak hemşirelik yaklaşımı, bireyin ölüme yönelik duygu ve düşüncelerinin ifadesinin sağlanması olmalıdır. Bireylerin bu süreçte kendini ifade etmesinin sağlanması, hemşirenin yargılayıcı bir tutumla yaklaşmadan kendisini dinlediğini, anladığını ifade ederek hasta ve kendi arasında güven duygusunu geliştirmesi çok önemlidir. Bireyin ölüme yönelik kaygı duymasına neden olan faktörler sorgulanarak, bu kaygıyı ifade etmeleri sağlanmalıdır. Ayrıca bireyin ölüme ilişkin acı çekme ve ölümden sonraki hayata yönelik düşünceleri sorgulanarak spiritüel ilişkileri değerlendirilmelidir. ${ }^{[41,49,51]}$

İmplante edilebilir kardiyoverter defibrilatörler bireylere kalıcı olarak uygulanan cihaz yardımı ile gerçekleştirilen bir tedavi yöntemi olması nedeniyle bireylerin cihaza uyumları gerekmekte ve bu durum bireylerde mevcut kaygı düzeylerini daha da artırabilmektedir. ${ }^{[9]}$ Hemşirelerin, bireylerin cihaza yönelik yaşadığı problemleri bilmesi ve buna ilişkin girişimleri uygulaması ile bireylerin cihaza uyumlarının sağlanması gerekmektedir. Öncelikli olarak hastaların cihaza ilişkin ne tür problemler yaşadığının sorgulanması ve her soruna ilişkin bireye özgü yaklaşımların uygulanması önem taşımaktadır. Hasta ve ailesinin ICD'nin takılma nedeni, işleyişi, dikkat etmeleri gereken hususlar ve doktora başvurmaları gereken durumlar konusunda bilgilendirmeleri gerekmektedir. ${ }^{[18,29]}$ Bu sayede bireylerin daha önce hiç kullanmadıkları bir cihaza yönelik yaşayabilecekleri kaygı düzeyleri azaltılabilecektir.

Bireylerin özellikle ölüm ile karşı karşıya kalma ya da fiziksel yetilerini yitirme durumunda artan ölüm kaygısı nedeniyle destek sistemleri sorgulanmalı ve sosyal destek mümkün olduğunca sağlanmalıdır. Buna yönelik hasta yakınları ile konuşularak bireyin kaygılarına ilişkin bilgilendirilmeleri ve destek sisteminin önemi aktarılmalıdır. Tüm bu girişimler sırasında hemşirenin de kendi duygu ve düşüncelerinin farkındalığı oldukça önemlidir. Çünkü hemşirelerin de mevcut düşüncelerinin hasta ve hasta yakınlarını olumlu ya da olumsuz etkileyebileceği unutulmamalı, mümkün olduğunca profesyonel yaklaşım sağlanmalıdır. ${ }^{[48,49,51]}$

Ölüme yönelik hemşirenin tutumu, hasta ve hasta yakınlarına verilen bakımı önemli düzeyde etkileyebilmektedir. Bu nedenle ölüm ve ölüme ilişkin olumsuz ifadelerin kullanımından kaçınılmalı ve çoğunlukla hasta ve hasta yakınlarının ifadesi etmesi sağlanmalıdır. Hastanın özellikle kendini iyi hissettiği geçmişe yönelik anıları sorgulanmalı ve olumlu düşüncelerin gelişmesi sağlanmalıdır. ${ }^{[48,49,51,58]}$

Dougherty ve ark. (2005) ICD hastaları ile yapmış oldukları çalışmada, 12 aylık telefon ile uygulanan eğitsel hemşirelik müdahalelerinin hastaların endişe, kaygı, ölüm kaygısı ve öz yeterliklerine ilişkin etkili bir iyileşme sağladığı belirlenmiştir. ${ }^{[11]}$ Ancak devamlı ve etkili bir hemşirelik bakımı ile bireylerin kaygı düzeyleri ve buna ilişkin gelişen şoklar azaltılabilir, $\mathrm{KVH}^{\prime}$ ye ilişkin mortalite oranları iyileştirilebilir. Ayrıca ölüme yönelik düşüncelerin yeniden yapılandırılması ve olumlu bakış açısının kazandırılması mümkün olabilir. Hemşirelerin hasta ve hasta yakınlarına ilişkin bütüncül bir bakım verebilmesi, hastaları ve yakınlarını etkileyen tüm problemleri aynı anda ele alarak müdahale etmesi ve bakımının devamlılığını sürdürmesi ile mümkündür. ${ }^{[51,58]}$

\section{Sonuç}

Kalp hastalığı olduğunu öğrenen bir bireyin aklına ilk olarak gelen kavramlardan biri ölümdür. Çünkü bireyler için kalp yaşamın sürdürülmesinde oldukça önem teşkil eden bir organdır. Özellikle ICD hastalarında olduğu gibi yaşamı tehdit eden hastalığı olan bireylerde yaşama ilişkin kontrol ve bağımsızlık fonksiyonlarının kaybedilmesi düşüncesi ölüme 
yönelik çaresizlik ve kaygı duyularını tetikler. ${ }^{[41,49]}$ Aşırı ve kontrolsüz gelişen bu ölüm düşünceleri ilerleyen süreçlerde bireylerin psikolojisini olumsuz yönde etkiler ve depresyona neden olabilir. Sınırlandırılmayan kaygı düşüncesi artarak bireylerin ruhsal dengesini bozar, günlük yaşamlarını ve iş yaşamlarını etkiler, bireyleri bağımlı hale getirebilir ve bireyin hayata ilişkin sevinci ve gücünü azaltabilir. ${ }^{[56,59]} \mathrm{Bu}$ nedenle bireylerin ölüme ilişkin düşüncelerinin ve buna yönelik kaygı düzeylerinin azaltılması önemlidir.

Bireylerin kaygı düzeylerinin belirlenmesi ve azaltılmasında en büyük rol başta hemşireler olmak üzere sağlık çalışanlarına düşmektedir. Hemşirelerin kalp hastalığı olan ve buna ilişkin tedavisi süren bireylerde ölüm kaygısı düzeylerinin değerlendirilmesi gerekliliğinin farkında olması ve buna yönelik girişimlerini planlaması gerekmektedir. Bu sayede ICD hastaları gibi özellikle kalp hastalığı olan bireylerde artan kaygının yol açabileceği problemlerin engellenebileceği ve hastaların yaşama yönelik bakış açılarının iyileştirilerek tedavinin devamlıığının ve etkililiğinin sağlanabileceği hem yaşam kalitelerinin hem de sunulan sağlık hizmetinin kalitesinin arttırılabileceği düşünülmektedir.

Hakem Değerlendirmesi: Dış bağımsız.

Çıkar Çatışması: Yazarlar arasında herhangi bir çıkar çatışması bulunmamaktadır.

Yazarlık Katkıları: Konsept: M.S., Z.Ö.; Dizayn: M.S., Z.Ö.; Veri Toplama veya İşleme: M.S., Z.Ö.; Analiz veya Yorumlama: M.S., Z.Ö.; Literatür Tarama: M.S., Z.Ö.; Yazan: M.S., Z.Ö.

\section{Kaynaklar}

1. WHO. Cardiovascular diseases . Available at: https://www. who.int/health-topics/cardiovascular-diseases/ Accessed 16 Sep 2019.

2. WHO.World Heart Day. Available at: http://www.who.int/cardiovascular_diseases/world-heart-day/en/ Accessed 25 October 2018.

3. T.C. Sağlık Bakanlığı. Türkiye Kalp Ve Damar Hastalıkları Önleme Ve Kontrol Programı Eylem Planı 2015-2020. Available at: https://www.tkd.org.tr/TKDData/Uploads/files/Turkiye-kalp-ve-damar-hastaliklari-onleme-ve-kontrol-programi. pdf Accessed 16 Sep 2019.

4. WHO. Global Status Report On Noncommunicable Diseases. 2015. Available at: https://www.who.int/gho/publications/ mdgs-sdgs/MDGs-SDGs2015_chapter6.pdf?ua=1. Accessed Sep 20, 2019.

5. Moss AJ, Greenberg H, Case RB, Zareba W, Hall WJ, Brown MW, et al. Long-term clinical course of patients after termination of ventricular tachyarrhythmia by an implanted defibrillator. Circulation 2004;110:3760-5.
6. Al-Khatib SM, Stevenson WG, Ackerman MJ, Bryant WJ, Callans DJ, Curtis AB, et al. 2017 AHA/ACC/HRS Guideline for Management of Patients With Ventricular Arrhythmias and the Prevention of Sudden Cardiac Death. Circulation 2018;138:e272e391.

7. Dickerson SS, Posluszny M, Kennedy MC. Help Seeking in a Support Group For Recipients Of İmplantable Cardioverter Defibrillators And Their Support Persons. Hear Lung 2000;29:87-96.

8. Lewin RJ, Coulton S, Frizelle DJ, Kaye G, Cox H. A brief cognitive behavioural preimplantation and rehabilitation programme for patients receiving an implantable cardioverter-defibrillator improves physical health and reduces psychological morbidity and unplanned readmissions. Heart 2008;95:63-9.

9. Burns JL, Serber ER, Keim S, Sears SF. Measuring patient acceptance of Implantable cardiac device therapy: initial psychometric investigation of the Florida Patient Acceptance Survey. J Cardiovasc Electrophysiol 2005;16:384-90.

10. Salmoirago-Blotcher E, Ockene IS. Methodological limitations of psychosocial interventions in patients with an implantable cardioverter-defibrillator (ICD) A systematic review. BMC Cardiovasc Disord 2009;9:56.

11. Dougherty CM, Thompson EA, Lewis FM. Long-term outcomes of a telephone intervention after an ICD. Pacing Clin Electrophysiol 2005;28:1157-67.

12. Dunbar SB, Warner CD, Purcell JA. Internal cardioverter defibrillator device discharge: experiences of patients and family members. Heart Lung 1993;22:494-501.

13. Carroll DL, Hamilton GA. Long-term effects of implanted cardioverter-defibrillators on health status, quality of life, and psychological state. Am J Crit Care 2008;17:222-30; quiz 231.

14. Schron EB, Exner DV, Yao Q, Jenkins LS, Steinberg JS, Cook JR, et al. Quality of life in the antiarrhythmics versus implantabledefibrillators trial: impact of therapy and influence of adverse symptoms and defibrillator shocks. Circulation 2002;105:58994.

15. Sears SE, Conti JB. Understanding implantable cardioverter defibrillator shocks and storms: medical and psychosocial considerations for research and clinical care. Clin Cardiol 2003;26:107-11.

16. Bostwick JM, Sola CL. An updated review of implantable cardioverter/defibrillators, induced anxiety, and quality of life. Psychiatr Clin North Am 2007;30:677-88.

17. Flemme I, Bolse K, Ivarsson A, Jinhage BM, Sandstedt B, Edvardsson $\mathrm{N}$, et al. Life situation of patients with an implantable cardioverter defibrillator: a descriptive longitudinal study. J Clin Nurs 2001;10:563-72.

18. Bell L. Care of Patients With an Implanted Cardiac Device. Am J Crit Care 2008;17:453-4.

19. Sears SF, Matchett M, Conti JB. Effective management of ICD patient psychosocial ıssues and patient critical events. J Cardi- 
ovasc Electrophysiol 2009;20:1297-304.

20. Sears SF Jr, Shea JB, Conti JB. Cardiology patient page. How to respond to an implantable cardioverter-defibrillator shock. Circulation 2005;111:e380-2.

21. Mirowski M, Mower MM, Langer A, Heilman MS, Schreibman J. A chronically implanted system for automatic defibrillation in active conscious dogs. Experimental model for treatment of sudden death from ventricular fibrillation. Circulation 1978;58:90-4.

22. Mirowski M, Reid PR, Mower MM, Watkins L, Gott VL, Schauble JF, et al. Termination of malignant ventricular arrhythmias with an implanted automatic defibrillator in human beings. $\mathrm{N}$ Engl J Med 1980;303:322-4.

23. Fetzer SJ. The patient with an Implantable cardioverter defibrillator. J perianesthesia Nurs 2003;18:398-413.

24. Zipes DP, Roberts D. Results of the international study of the implantable pacemaker cardioverter-defibrillator. A comparison of epicardial and endocardial lead systems. The Pacemaker-Cardioverter-Defibrillator Investigators. Circulation 1995;92:59-65.

25. Myerburg RJ, Reddy V, Castellanos A. Indications for implantable cardioverter-defibrillators based on evidence and judgment. J Am Coll Cardiol 2009;54:747-63.

26. Pedersen CT, Kay GN, Kalman J, Borggrefe M, Della-Bella P, Dickfeld T, et al. EHRA/HRS/APHRS expert consensus on ventricular arrhythmias. Heart Rhythm 2014;11:e166-96.

27. Medtronic. Implante Edilebilen Kardiyoverter Defibrilatörünüz İçin Hasta El Kitabı. Available at: http://demirmedikal. com.tr/Defibrilator-El-Kitabi.pdf Accessed 16 Sep 2019.

28. Dunbar SB, Dougherty CM, Sears SF, Carroll DL, Goldstein $\mathrm{NE}$, Mark DB, et al. Educational and psychological interventions to improve outcomes for recipients of implantable cardioverter defibrillators and their families: a scientific statement from the American Heart Association. Circulation 2012;126:2146-72.

29. Sossong A. Living with an implantable cardioverter defibrillator: patient outcomes and the nurse's role. J Cardiovasc Nurs 2007;22:99-104.

30. Sola CL, Bostwick JM. Implantable cardioverter-defibrillators, induced anxiety, and quality of life. Mayo Clin Proc 2005;80:232-7.

31. Matchett M, Sears SF, Hazelton G, Kirian K, Wilson E, Nekkanti R. The implantable cardioverter defibrillator: its history, current psychological impact and future. Expert Rev Med Devices 2009;6:43-50.

32. Dougherty CM, Pyper GP, Frasz HA. Description of a nursing intervention program after an implantable cardioverter defibrillator. Hear Lung 2004;33:183-90.

33. Beery TA, Sommers MS, Hall J. Focused life stories of women with cardiac pacemakers. West J Nurs Res 2002;24:7-23

34. Karadeniz G, Altıparmak S, Aydemir Ö, Karadağ F. Koroner An- jiografi Öncesi Anksiyete ve Depresyon. Psikofarmakol Derg 2005;13:43-7.

35. Aydemir Ö. Dahiliye ve Psikiyatri 1: Kalp Damar Hastalıkları, Depresyon ve Anksiyete Bozuklukları. 1st ed. İstanbul, Okyanus Yayınları, 2002.

36. Balcı A, Enç N. Koroner Anjiyografi Uygulanacak Hastalara Verilen Görsel-İşitsel Eğitimin Fizyolojik ve Psikososyal Parametreler Üzerine Etkisi. Turk Soc Cardiol Turkish Journal of Cardiovascular Nursing 2013;4:41-50.

37. Gibson DP, Kuntz KK. Managing Anxiety in Patients With The Implanted Cardiac Defibrillators. Curent Psychiatry 2007;6:1728.

38. Kuhl EA, Dixit NK, Walker RL, Conti JB, Sears SF. Measurement of patient fears about implantable cardioverter defibrillator shock: an initial evaluation of the Florida Shock Anxiety Scale. Pacing Clin Electrophysiol 2006;29:614-8.

39. Ahmad M, Bloomstein L, Roelke M, Bernstein AD, Parsonnet V. Patients' attitudes toward implanted defibrillator shocks. Pacing Clin Electrophysiol 2000;23:934-8.

40. Mert H, Argon G, Aslan Ö. Experiences of patients with implantable cardioverter defibrillator in Turkey: A qualitative study. Int J Caring Sci 2012;5:50-6.

41. Küçük L. Kalp Hastalarında Ruhsal Sorunlar ve Bakımın Psikososyal Boyutu. Yoğun Bakım Hemşireliği Derg 2007;11:4851.

42. Duru F, Büchi S, Klaghofer R, Mattmann H, Sensky T, Buddeberg $C$, et al. How different from pacemaker patients are recipients of implantable cardioverter-defibrillators with respect to psychosocial adaptation, affective disorders, and quality of life? Heart 2001;85:375-9.

43. Schuster PM, Phillips S, Dillon DL, Tomich PL. The psychosocial and physiological experiences of patients with an implantable cardioverter defibrillator. Rehabil Nurs 1998;23:30-7.

44. Hussein NA, Thomas MA. Rehabilitation of patients with implantable cardioverter/defibrillator: a literature review. Acta Cardiol 2008;63:249-57.

45. Undavia M, Goldstein NE, Cohen P, Sinthawanarong K, Singson $M$, Bhutani $D$, et al. Impact of implantable cardioverter-defibrillator recalls on patients' anxiety, depression, and quality of life. Pacing Clin Electrophysiol 2008;31:1411-8.

46. Kamphuis HC, Verhoeven NW, Leeuw R, Derksen R, Hauer RN, Winnubst JA. ICD: a qualitative study of patient experience the first year after implantation. J Clin Nurs 2004;13:1008-16.

47. Türk Dil Kurumu. Türkçe Sözlük. Türk Dil K. 2013. Available at: http://www.tdk.gov.tr/index.php?option=com_bts. Accessed Sep 20, 2019.

48. Arpacı F, Avdaş E, Doğruöz Ö, Sarıdoğan T. Yaşlılarda Ölüm Kaygısının İncelenmesi. Yaşlı Sorunları Araştırma Derg 2011;1:5366.

49. Şahin M, Demirkıran F, Adana F. Nursing Students' Death Anxiety, Influencing Factors and Request of Caring For Dying 
People. J Psychiatr Nurs 2016;7:135-41.

50. Türk Dil Kurumu Yayınları: Atatürk Kültür Dil ve Tarih Yüksek Kurumu. Hemşirelik Terimleri Sözlüğü. Available at: http:// www.tdk.gov.tr/index.php?option=com_hemsirelik\&view=hemsirelik Accessed 16 Sep 2019.

51. Juall Carpenito L. Hemşirelik Tanıları El Kitabı. İstanbul, Nobel Tıp Kitabevleri; 2010.

52. Collett LJ, Lester D. The fear of death and the fear of dying. J Psychol 1969;72:179-81.

53. Chuin CL, Choo YC. Age, Gender And Religiosity As Related To Death Anxiety. Sunw Acad J 2010;1-16.

54. Berg SK, Higgins M, Reilly CM, Langberg JJ, Dunbar SB. Sleep quality and sleepiness in persons with implantable cardioverter defibrillators: outcome from a clinical randomized longitudinal trial. Pacing Clin Electrophysiol 2012;35:431-43.

55. Habibović M, Mudde L, Pedersen SS, Schoormans D, Widdershoven J, Denollet J. Sleep disturbance in patients with an implantable cardioverter defibrillator: Prevalence, predictors and impact on health status. Eur J Cardiovasc Nurs 2018;17:390-8.

56. Tanhan F. Ölüm Eğitiminin Üniversite Öğrencilerinde Ölüm Kaygısı ve Psikolojik İyi Olmaya Etkisi. YYÜ Eğitim Fakültesi Derg 2013;x:184-200.

57. Fitchet A, Doherty PJ, Bundy C, Bell W, Fitzpatrick AP, Garratt CJ. Comprehensive cardiac rehabilitation programme for implantable cardioverter-defibrillator patients: a randomised controlled trial. Heart 2003;89:155-60.

58. Yılmaz E, Kutlu AK, Çeçen D. Cerrahi Kliniklerinde Yatan Hastaların Uyku Durumlarını Etkileyen Faktörler. Yeni Tıp Derg 2008;25:149-56.

59. Tanhan F, Arı F. Üniversite Öğrencilerinin Ölüme Verdikleri Anlam Ve Öğrenim Gördükleri Program Açısından Ölüm Kaygısı Düzeyleri. Yüzüncü Yıl Üniversitesi Eğitim Fakültesi Derg 2006;:111:34-43. 